\title{
Inter-island dispersal of flightless Bothrometopus huntleyi (Coleoptera: Curculionidae) from the sub-Antarctic Prince Edward Island archipelago
}

\author{
G.C. GROBLER ${ }^{1}$, A.D.S. BASTOS ${ }^{1,2}$, C.T. CHIMIMBA ${ }^{1,3}$ and S.L. CHOWN ${ }^{3}$ \\ ${ }^{1}$ Department of Zoology and Entomology, University of Pretoria, Pretoria 0002, South Africa \\ ${ }^{2}$ Department of Biological Sciences, University of Cyprus, Nicosia, Cyprus \\ ${ }^{3}$ Centre for Invasion Biology, Department of Botany and Zoology, Stellenbosch University, Private Bag X1, Matieland 7602, South Africa \\ gcgrobler@gmail.com
}

\begin{abstract}
Bothrometopus huntleyi is a flightless weevil endemic to the volcanically-formed sub-Antarctic Prince Edward Islands archipelago that arose approximately 0.5 million years ago (m.y.a.). Since emergence, a series of volcanic and glaciation events have occurred on Marion Island, whilst Prince Edward Island, the second island constituting the archipelago, has remained largely unaffected by glaciation. Cytochrome oxidase I gene analyses indicate that major historical dispersal events in this species are linked to the geologically discrete histories of these islands and underlie the high haplotype diversity (0.995) recovered for the Prince Edward Islands archipelago. The estimated time to haplotype coalescence of $\sim 0.723$ m.y.a. is in keeping with estimated dates of island emergence, and the majority of individuals appear to have descended from a relict, high-altitude population that is still present on Marion Island. The first major inter-island dispersal event occurred $\sim 0.507$ m.y.a., coinciding with the oldest dated rocks on Marion Island. Apart from this early inter-island colonization, only one other between-island dispersal event was detected. The genetically discrete $B$. huntleyi complexes on each of the islands of the Prince Edward Islands archipelago together with the low levels of inter-island gene flow reaffirm the need to control alien invasive mice, which are restricted to Marion Island, and which prey on this weevil species.
\end{abstract}

Received 28 August 2009, accepted 28 October 2010, first published online 25 February 2011

Key words: COI gene, conservation biogeography, invasion biology, mtDNA, phylogeography

\section{Introduction}

Bothrometopus huntleyi (Grobler et al. 2011) (Curculionidae: Coleoptera: Hexapoda) belongs to the Ectemnorhinus group of genera (Kuschel \& Chown 1995), also known as the tribe Ectemnorhinini (Alonso-Zarazaga \& Lyal 1999), which is restricted to islands of the sub-Antarctic South Indian Ocean Province (SIP). This group of weevils comprises eight genera and 37 flightless species (Kuschel \& Chown 1995, Grobler et al. 2006, 2011), of which seven occur on the Prince Edward Islands. Of these seven species, five, including $B$. huntleyi, are endemic to the archipelago, with Bothrometopus randi (Jeannel 1953) also being found on the Iles Crozet to the east, and Palirhoeus eatoni (C.O. Waterhouse 1876) occurring on all SIP islands (Kuschel \& Chown 1995). Recent molecular studies both of this group of weevils (Grobler et al. 2006) and of other taxa in the region (e.g. Stevens et al. 2006, Myburgh et al. 2007) have suggested that relationships among species, within and among islands and archipelagos (including the Prince Edward Island archipelago) may be much more complex than suggested by morphological analyses. In consequence, it may be argued that the status of $B$. huntleyi on the Prince Edward Island archipelago has not been fully resolved, and that it might be expected to show substantial phylogeographic structure associated with the different histories of the two islands which lie only $19 \mathrm{~km}$ apart. Perhaps most significantly, Marion Island, the larger of the two Prince Edward Islands, was extensively glaciated whilst the smaller Prince Edward Island shows no evidence of glaciation (Boelhouwers et al. 2008). McDougall et al. (2001) suggested that Marion Island had five distinct cold periods and eight volcanic ages, with two of these accompanying major glaciations (Fig. 1). Although the exact sequence and spatial extent of volcanic and glacial events is currently the subject of revision, this overall scenario appears to be robust (Boelhouwers et al. 2008).

In consequence, substantial differences among populations of $B$. huntleyi on the two islands might be expected. Such differences would not only be of biogeographic significance (see e.g. Chown 1992), but would also have substantial conservation implications given the differences in invasive alien species on the islands, especially the absence of house mice on Prince Edward Island, which have a dietary preference for weevils on Marion Island (Chown \& Smith 1993). Here we set out to examine the evolutionary dynamics shaping the population structure of $B$. huntleyi, which occurs on both islands, is widely distributed across Marion Island, and has until recently been confounded with $B$. parvulus (Grobler et al. 2011). 


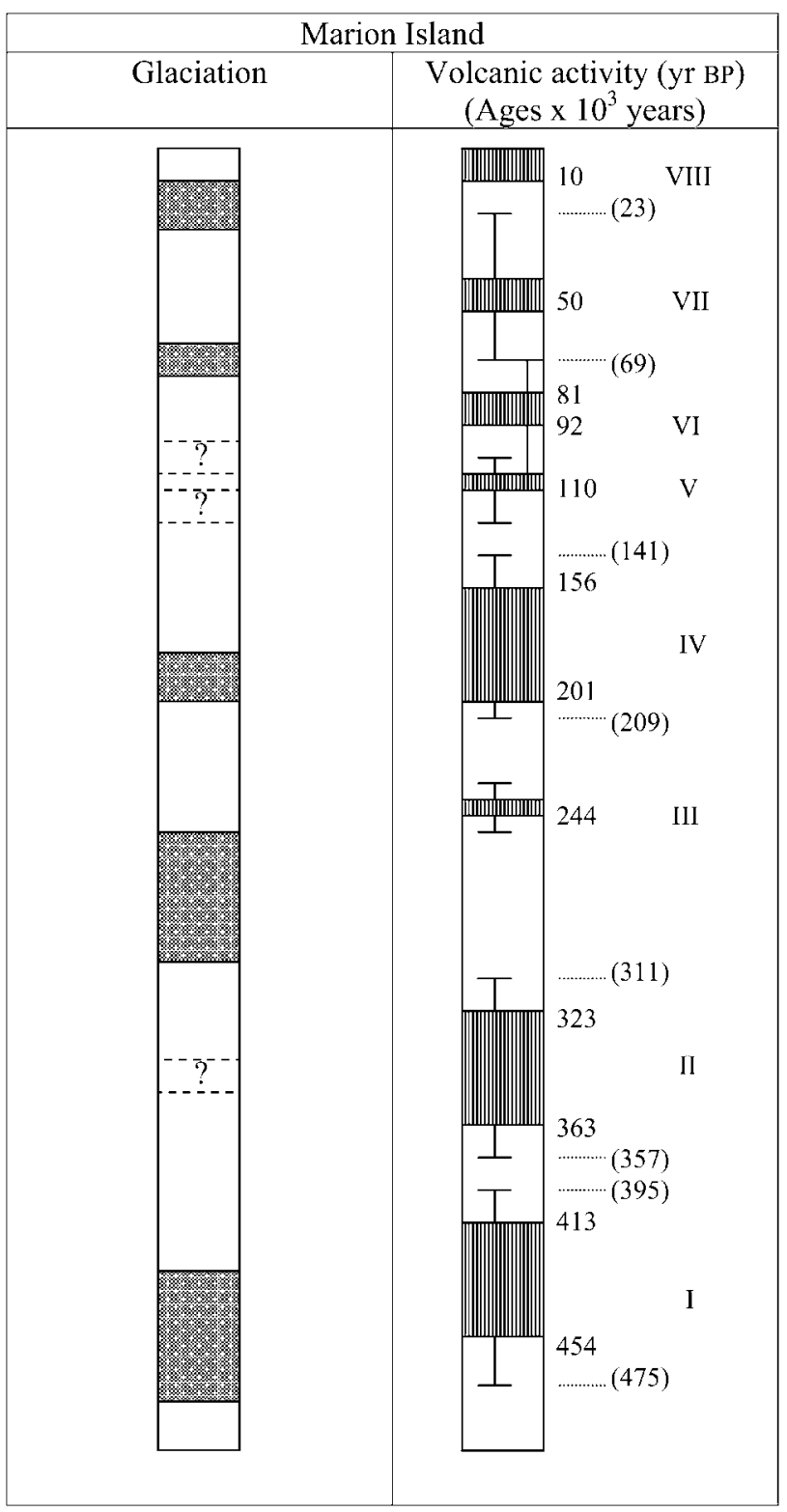

Fig. 1. Correlation of volcanic activity and glaciation on Marion Island. The shaded bars represent periods of glaciation or volcanic activity with the older events at the bottom of the figure and the most recent events at the top. This diagram is presented with the permission of the Geological Magazine and Professor McDougall (McDougall et al. 2001).

\section{Materials and methods}

\section{Systematics and biology}

Although the genus Bothrometopus has previously been separated into two distinct groups, the fasciatus- and gracilipes-groups, which are distinguished by, respectively, the absence and presence of vaginal spicules (see Dreux \& Voisin 1984, 1986, Kuschel \& Chown 1995 for earlier work on the genus and its now synonymous allies), Grobler et al. (2011) have called for the re-evaluation of these groups.
Because $B$. huntleyi was previously not distinguished from the very similar $B$. parvulus, and because it is now clear that $B$. parvulus is restricted to coastal areas of both islands (Grobler et al. 2011), it can be reasonably assumed, from the previous literature on habitat use in the group (e.g. Chown 1989), that B. huntleyi predominantly occurs in epilithic moss cushions from coastal rock faces to high-altitude fellfield and polar desert. The larvae and adults feed on algae, lichens, and bryophytes (Chown 1989, 1992). Individuals may occur occasionally on Azorella selago, but feed on epiphytic algae and bryophytes, rather than on the plant itself (Chown 1989, 1992). On both Marion Island and Prince Edward Island, $B$. huntleyi shows distinct variation in size, associated both with elevation and habitat type, although differences among the two islands are not pronounced (Chown 1992, Chown \& Smith 1993, Chown \& Klok 2003).

\section{Study sites and sampling}

Specimens of $B$. huntleyi were collected during three consecutive years (April 2001-April 2003) from 14 localities from the eastern side of Marion Island (Fig. 2). Due to restricted access to Prince Edward Island, weevils were only sampled from five localities on one occasion in April 2003 (Fig. 2). For each island, the specimens were collected from a range of altitudes, and individuals selected for genetic characterization were chosen to ensure the broadest possible size and colour variation representation, for each sampling locality. The geographic coordinates, altitude and weevil size range recorded for each sampling locality are summarized in Table I. All specimens were collected by hand and preserved in absolute ethanol. Bothrometopus brevis (C.O. Waterhouse) from Heard Island was selected as an outgroup, since it is the closest known sister taxon of B. huntleyi (Grobler et al. 2011, Table I).

\section{Genetic characterization}

DNA from each individual was extracted from a single leg which, following removal from ethanol was washed and rehydrated in distilled water for 10 minutes, prior to being frozen in liquid nitrogen and ground using an Eppendorf micro pestle (Merck, South Africa). DNA was extracted using the High Pure PCR Template Preparation Kit (Roche Applied Science) using the supplier's procedure for the isolation of nucleic acids from mammalian tissue with modification to the proteinase $\mathrm{K}$ tissue lysis incubation step, which was performed for $48 \mathrm{hr}$ instead of the recommended $1 \mathrm{hr}$ for mammalian tissue.

COI primers, GF-1858 and GR1-2938 which are specific for weevils from Marion Island (Grobler et al. 2006) were used to amplify a $1059 \mathrm{bp}$ PCR product under previously described reaction conditions (Grobler et al. 2006) using a thermal cycling profile that consisted of an initial denaturation step at $94^{\circ} \mathrm{C}$ for $90 \mathrm{~s}$, followed by 40 cycles of $94^{\circ} \mathrm{C}$ for $22 \mathrm{~s}$, 


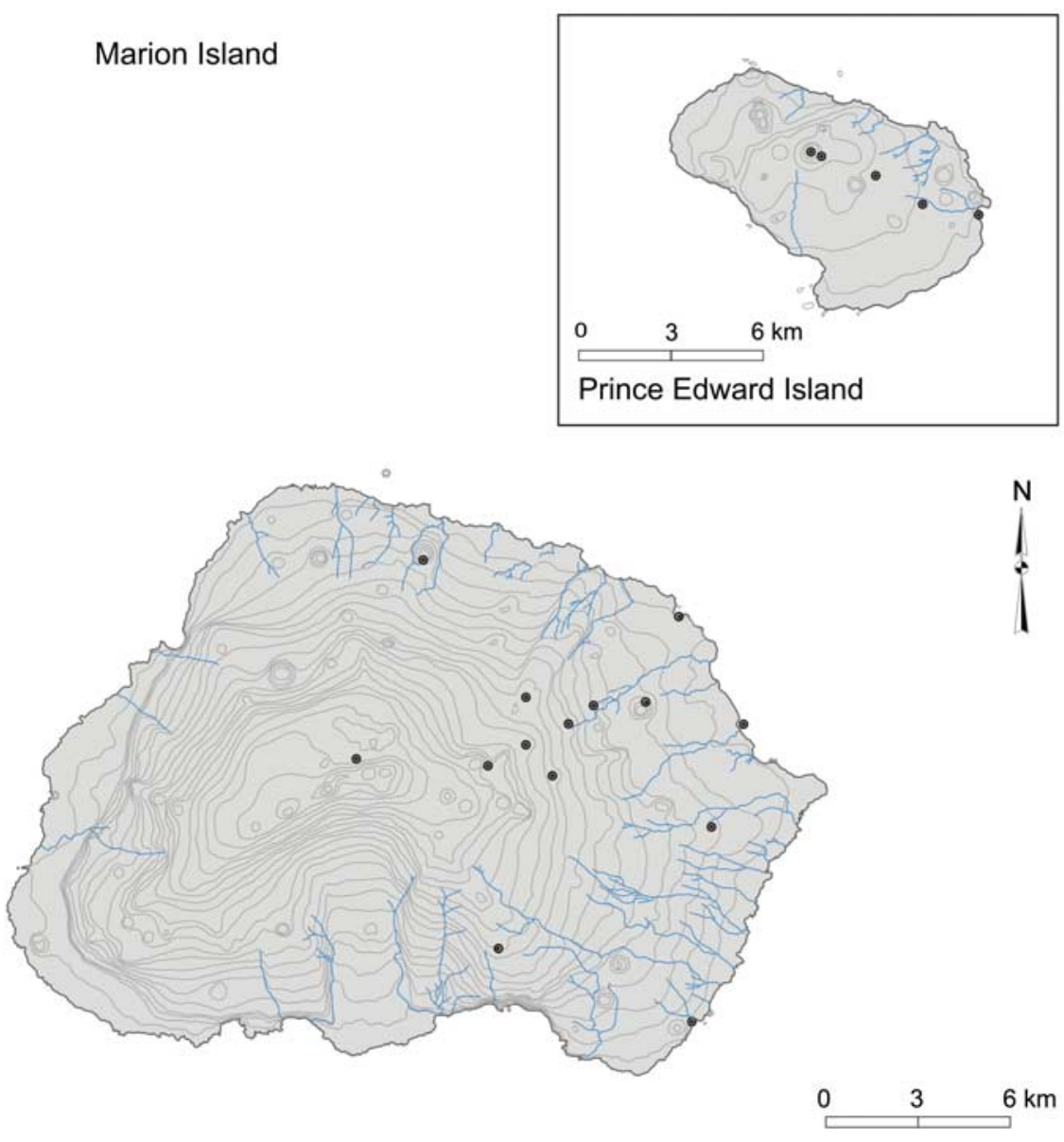

Fig. 2. Map indicating flightless weevil (Bothrometopus huntleyi) sampling localities on the Prince Edward Island archipelago and that correspond to the geographic coordinates summarized in Table I.

Table I. Summary of the 19 sampling localities on Marion Island (MI) and Prince Edward Island (PEI) from which the genetically characterized Bothrometopus huntleyi specimens included in this study were collected.

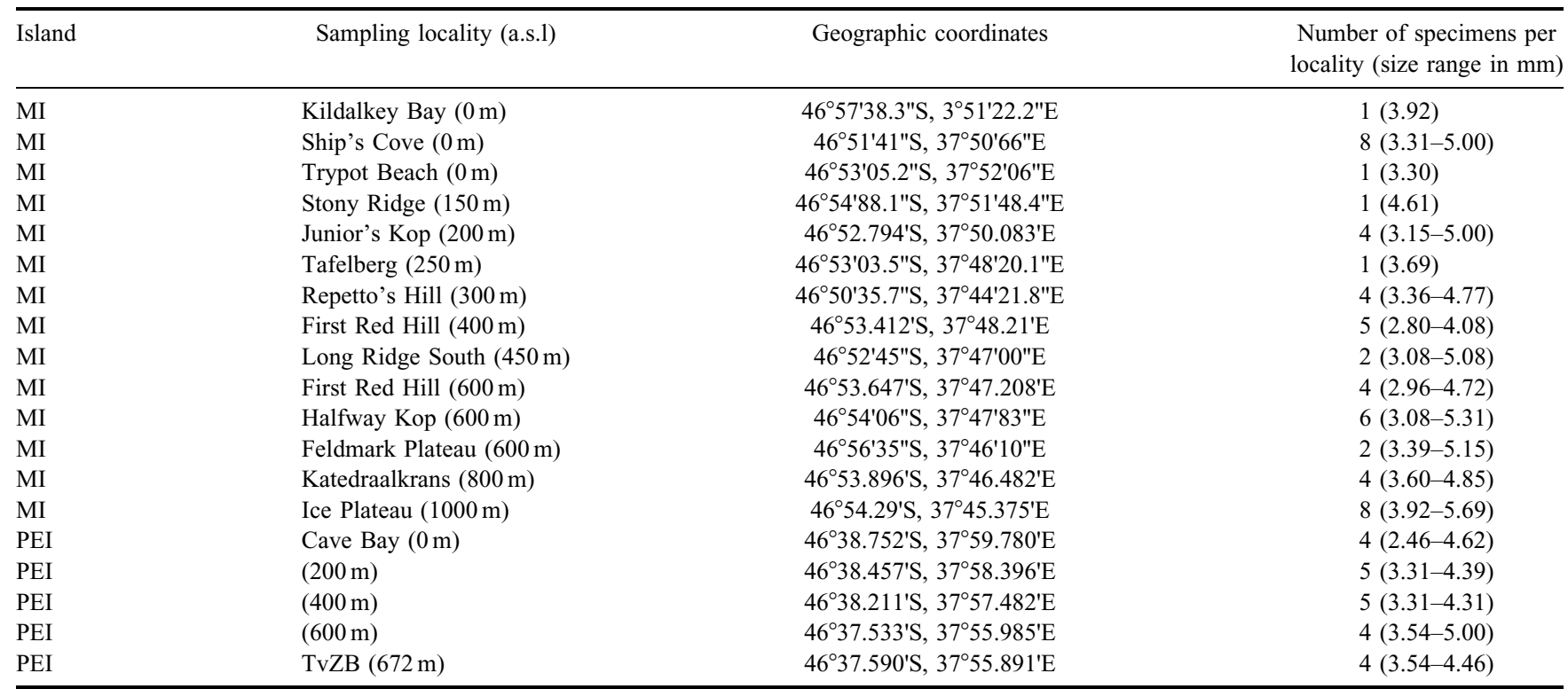

a.s.l. = above sea level, TvZB $=$ samples collected at the top of Van Zinderen Bakker. 
$46^{\circ} \mathrm{C}$ for $30 \mathrm{~s}$ and $72^{\circ} \mathrm{C}$ for $1 \mathrm{~min}$ and concluding with a final extension step of $1 \mathrm{~min}$ at $72^{\circ} \mathrm{C}$. PCR products of the correct size were purified directly from the tube using a Roche High Pure PCR Product Purification Kit (Roche Applied Science). Automated cycle sequencing with the ABI PRISM Big Dye $^{\mathrm{TM}}$ Terminator version 3.0 (Applied Biosystems) and two internal primers, GF5-1940 and GR5-2935 (Grobler et al. 2006), in separate reactions, was performed at an annealing temperature of $46^{\circ} \mathrm{C}$. Sequences were viewed, edited and aligned in MEGA4 (Tamura et al. 2007), resulting in a homologous dataset $885 \mathrm{bp}$ in length.

\section{Phylogenetic analyses}

Neighbor-Joining (NJ) and Minimum Evolution (ME) algorithms were used to construct distance trees in MEGA4 (Tamura et al. 2007) and maximum likelihood analyses were performed in PhyML (Guindon \& Gascuel 2003) using the model of sequence evolution identified as the best-fit model under the Akaike Information Criterion (AIC) in ModelTest version 3.06 (Posada \& Crandall 1998). Nodal support was assessed by 100000 and 5000 bootstrap replications, respectively. Maximum parsimony (MP) analyses were performed in PAUP* v4.0b10 (Swofford 2003). Characters had equal weights in the initial analysis and were subsequently reweighted using the rescaled consistency index (RCI). Starting trees were obtained by random stepwise addition of sequences and branch swapping was performed using the tree-bisectionreconnection (TBR) algorithm. Bayesian Inference (BI) using MrBayes version 3.1 (Huelsenbeck \& Ronquist 2001) was performed using priors guided by the best-fit model and parameters in ModelTest (Posada \& Crandall 1998), namely the HKY85 model (Hasegawa et al. 1985) with the proportion of invariable sites (I) and gamma distribution shape parameter $(\Gamma)$ being 0.791 and 1.6671 , respectively. The analysis was initiated with random starting trees and run for 10000000 generations with Markov chains sampled every 2000 generations. Of the 5000 trees obtained, 1250 were discarded as "burn-in". Tracer plots were visually inspected and tracer diagnostics (standard deviation of split frequencies, effective sample size), as implemented in MrBayes and Tracer v1.4 (Drummond \& Rambaut 2007) were inspected to ensure that stationarity had been reached.

The equality of evolutionary rates between lineages was evaluated using the relative rate test (Li \& Bousquet 1992) in PHYLTEST version 2.0 (Kumar 1996). The likelihood ratio test (Felsenstein 1981, 1988) was also performed by calculating and comparing the log likelihood scores with and without the molecular clock enforced. Divergence times were estimated using the $2.3 \%$ nucleotide sequence divergence per million years, estimated from an arthropod mtDNA survey (Brower 1994) and the appropriate parameter-rich model of evolution (Papadopoulou et al. 2010) selected under the AIC in ModelTest (Posada \& Crandall 1998). BEAST 1.5.3
(Drummond \& Rambaut 2007) was used to obtain an ultrametric tree using Bayesian MCMC analysis orientated towards rooted, time-measured phylogenetics. Well supported nodes identified following NJ, ML and BI analyses were constrained to be monophyletic and the $\mathrm{HKY}+\mathrm{I}+\Gamma$ model was enforced using a strict molecular clock model. The results of two independent runs were merged and analysed with Tracer v1.4 and TreeAnnotator v1.4.7 (Drummond \& Rambaut 2007).

The program TCS version 1.21 (Clement et al. 2000) was used to generate a haplotype cladogram displaying the number of base pair differences between haplotypes. TCS version 1.21 (Clement et al. 2000) incorporates the cladogram estimation algorithm described by Templeton et al. (1992) and provides 95\% parsimoniously plausible branch connections between the different haplotypes.

\section{Mismatch analyses, population expansion and diversity estimates}

Pairwise mismatch distributions, where the observed pairwise mismatch distributions were fitted to a stepwise expansion model by a generalized least square procedure following Schneider \& Excoffier (1999), as implemented in Arlequin version 2.0 (Schneider et al. 2000), were generated. A constant size population is expected to show a ragged, multimodal distribution, while an expanding population is consistent with a smooth unimodal distribution. In each case, the raggedness index assesses the match of the real data to the model while the overall validity of the estimated expansion model was tested by comparing the distribution of the test statistic, SSD (sum of squared differences) between the observed and the estimated mismatch distribution using a bootstrap approach. Evidence for departure from the estimated expansion model is given by significant SSD values (Excoffier \& Schneider 1999).

The validity of a stepwise expansion model for the data was tested by Monte Carlo Markov chain simulations (1000 steps) in Arlequin version 2.0 (Schneider et al. 2000). The time of the main expansion in generations $(t)$ was estimated from the equation $\tau=2 \mu t$ using the moment estimator of time to the expansion $(\tau)$ computed in Arlequin version 2.0 (Schneider et al. 2000) and a mutation rate $(\mu)$ of $2.3 \%$ nucleotide sequence divergence per million years for arthropod mtDNA (Brower 1994). As the weevils complete one generation in one-year (Chown \& Scholtz 1989), $t$ could also be used as the time of the main expansion in years. Arlequin version 2.0 (Schneider et al. 2000) was utilized to estimate the essential population parameter $\theta$ using Watterson's (1975) estimate, which is based on the number of segregating sites among the sequences, and Tajima's (1983) estimate, which is based on the calculation of the mean number of pairwise differences of the sequences. Tajima's estimate of $\theta$ puts more weight on ancient mutations and therefore reflects ancient population events (Fu 1997). 


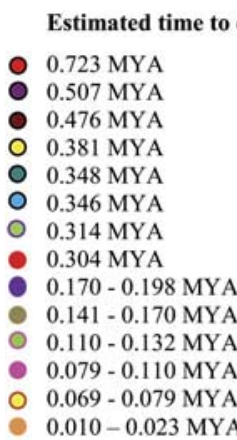

B. hutleyi 162-5: $3.60 \mathrm{~mm}, 800 \mathrm{~m}$, Katedraakrans, A. selago, M, MI 141-22: $4.31 \mathrm{~mm}, 300 \mathrm{~m}$, Repetto's Hill, Stones, M, M B. huntleyi 128-17: $5.31 \mathrm{~mm}, 600 \mathrm{~m}$, Halfway Kop, Stones, F, M B. huntleyi 170-1: $4.64 \mathrm{~mm}, 600 \mathrm{~m}$, First Red Hill, Stones, F, MI B. huntleyi 151-8: $5.00 \mathrm{~mm}, 200 \mathrm{~m}$, Junior's Kop, Stones, F, MI B. B. hunteyi 16-23:3.69 mm, 0 m, Ships Cove, Stones, M, MI B. B. huntleyi $175-6.3 .92 \mathrm{~mm}, 400 \mathrm{~m}$, First Red Hill, A. selago, F, MI B. hutleyi 170-18: $2.96 \mathrm{~mm}, 600 \mathrm{~m}$, First Red Hill, Stones, M, MI B. huntleyi 200-17: $4.85 \mathrm{~mm}, 800 \mathrm{~m}$, Katedraalkrans, Stones, F, MI B. huntleyi 170-16: $4.72 \mathrm{~mm}, 600 \mathrm{~m}$, First Red Hill, Stones, M, MI B. huntleyi 16-22: $3.46 \mathrm{~mm}, 0 \mathrm{~m}$, Ships Cove, Stones, F, MI B. huntleyi 355-11: $5.08 \mathrm{~mm}, 450 \mathrm{~m}$, Long Ridge S, Stones, F, M B. huntleyi 16-48: $4.08 \mathrm{~mm}, 0 \mathrm{~m}$, Ships Cove, Stones, F, MI 68/69/- Buntleyi 170-4: $3.04 \mathrm{~mm}, 600 \mathrm{~m}$, First Red Hill, Stones, M, MI 7-2: $3.30 \mathrm{~mm}, 0 \mathrm{~m}$, Tripot Beach, Stones, MI 84/81/100 B. huntleyi 141-30: $3.85 \mathrm{~mm}, 300 \mathrm{~m}$, Repetto's Hill, Stones, M, MI -195 B. huntleyi 141-25: $4.77 \mathrm{~mm}, 300 \mathrm{~m}$, Repetto's Hill, Stones, F, MI

huntleyi 151-5: $4.92 \mathrm{~mm}, 200 \mathrm{~m}$, Junior's Kop, Stones, F, MI $0.010-0.023$ MYA

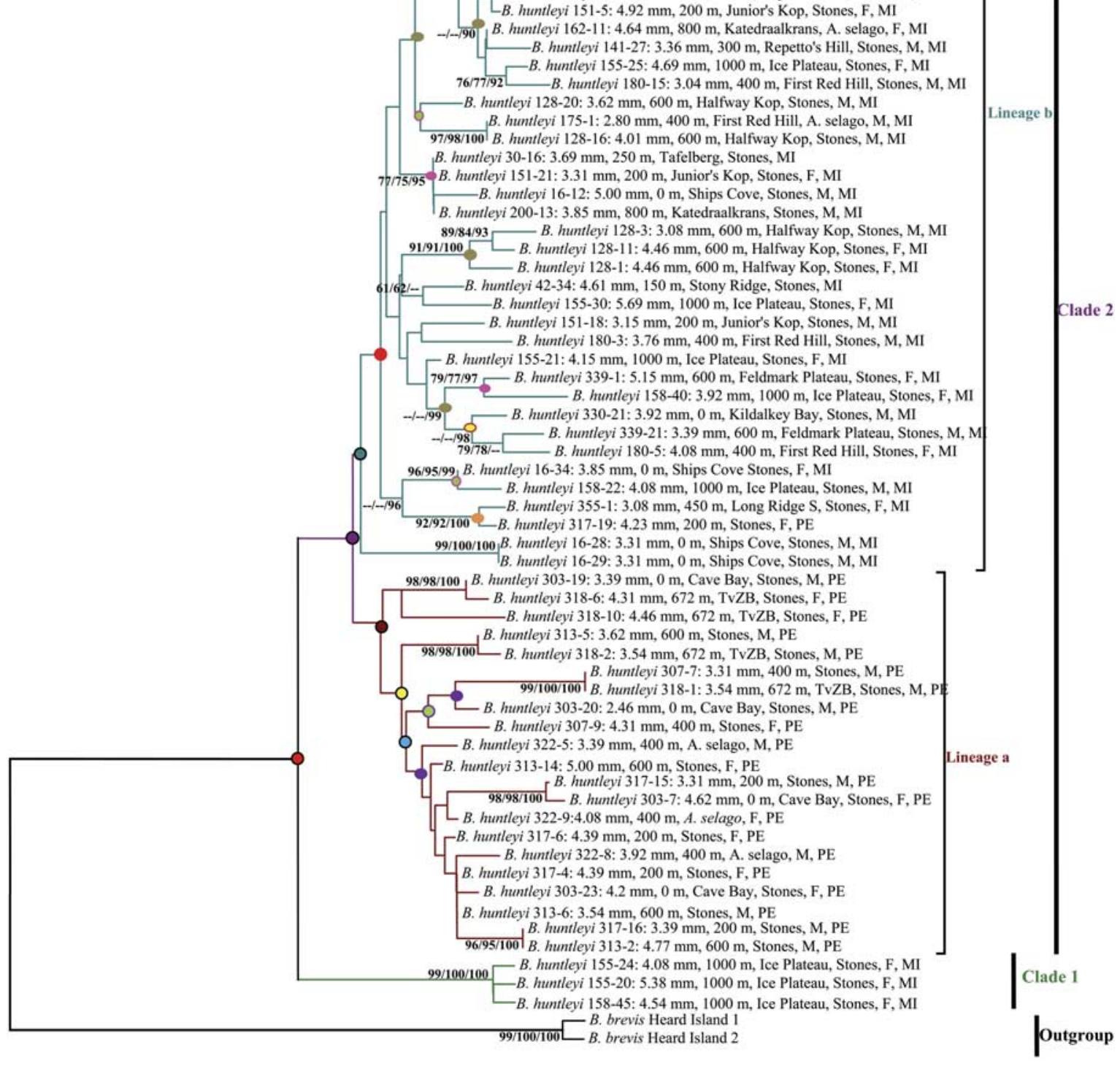

Fig. 3. Neighbour-Joining (NJ) tree of Bothrometopus huntleyi from Marion Island (MI) and Prince Edward Island (PEI) and B. brevis outgroup from Heard Island, based on 885 nucleotides of the mitochondrial cytochrome oxidase I (COI) gene inferred using the HKY85 model of sequence evolution. The taxon name contains the species designation, sample number, body length measurement, altitude and/or sampling locality, sex and island of origin. Nodal support values $\geq 60$ obtained from NJ and ML (100 000 and 5000 bootstrap replications, respectively) and $\geq 90$ from Bayesian Inference (BI) and expressed as a percentage, are indicated NJ/ML/BI. '--' denotes bootstrap support values below 60 (NJ and ML) and below 90 (BI). 


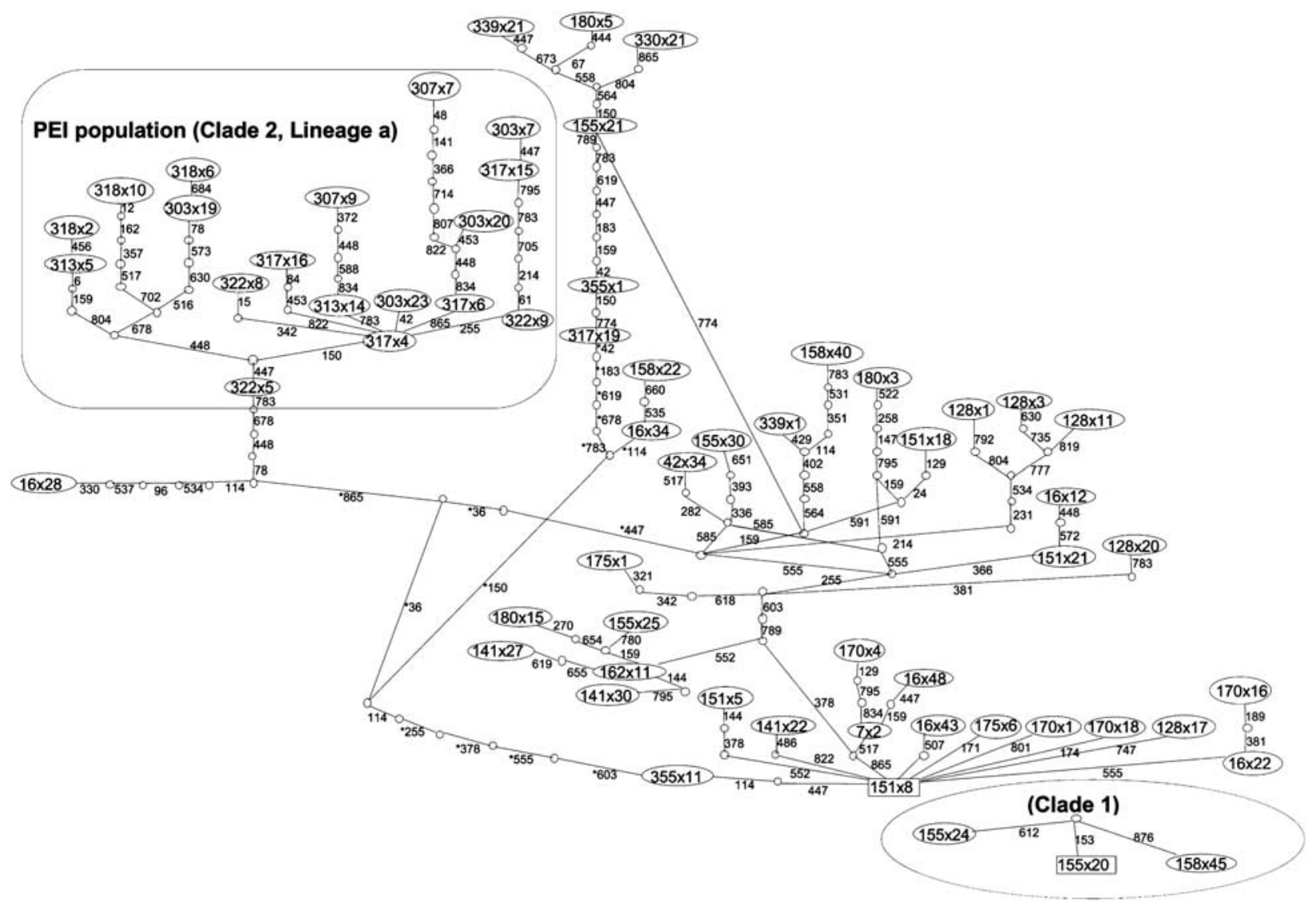

Fig. 4. Haplotype network of 73 Bothrometopus huntleyi individuals from Marion Island (MI) and Prince Edward Island (PEI) as estimated with TCS 1.21 (Clement et al. 2000).

Fu's (1997) $F_{S}$ test of neutrality, as estimated in Arlequin version 2.0 (Schneider et al. 2000), and the $R_{2}$ test of neutrality (Ramos-Onsins \& Rozas 2002), as estimated in DNASP version 5 (Librado \& Rozas 2009), were shown to be powerful tests for detecting recent population expansions under assumptions of neutrality with $R_{2}$ showing better results for small sample sizes and $F_{S}$ for large sample sizes. The $R_{2}$ statistic is based on the difference between the number of singleton mutations and the average number of nucleotide differences among sequences within a population sample (Ramos-Onsins \& Rozas 2002). The haplotype diversity (h) and nucleotide diversity $(\pi)$ were estimated in DNASP version 5 (Librado \& Rozas 2009).

\section{Results}

A homologous region of $885 \mathrm{bp}$ corresponding to the $5^{\prime}$ end of the COI gene was generated for $73 B$. huntleyi individuals and two B. brevis outgroup specimens. All sequences have been deposited in the Genbank database under accession numbers GQ131940-GQ132014. Of the 885 sites characterized, 768 were conserved across all 75 sequences and 82 of the 117 variable sites were parsimony informative. Under the $\mathrm{HKY}+\mathrm{I}+\Gamma$ model of sequence evolution, a transition (ti)/transversion (tv) ratio of 14.5 and base frequencies of $\mathrm{A}=0.3069, \mathrm{C}=0.1590, \mathrm{G}=0.1497$ and $\mathrm{T}=0.3844(\% \mathrm{AT}=70.2 \%)$ were recovered. Third base position substitutions accounted for $88.03 \%$ of the variation with $11.11 \%$ and $0.85 \%$ being due to first and second base substitutions, respectively. Mutations at the nucleotide level gave rise to five non-synonymous amino acid substitutions at codons 4, 191, 219, 238, and 289. Of the $73 \mathrm{~B}$. huntleyi individuals sequenced, 62 had unique haplotypes corresponding to a haplotype diversity (h) of 0.995 and a nucleotide diversity $(\pi)$ of 0.01278 for the Prince Edward Islands archipelago. When considering each island individually, 43 unique haplotypes were recovered from the 51 Marion Island specimens sequenced $(h=0.992$ and $\pi=0.01130$ ), whilst for Prince Edward Island, 19 unique haplotypes were identified from 22 individuals ( $\mathrm{h}=0.987$ and $\pi=0.00890$ ).

MP analysis recovered 76125 equally parsimonious trees with homoplasy indices of: $\mathrm{CI}=0.520, \mathrm{RI}=0.827$ and $\mathrm{RCI}=0.430$ when characters were assigned equal weights. Successive weighting with the RCI recovered the same number of equally parsimonious trees and homoplasy indices of $\mathrm{CI}=0.699, \mathrm{RI}=0.889$ and $\mathrm{RCI}=0.621$. All methods of phylogenetic inference (Fig. 3) revealed the presence of two 
a

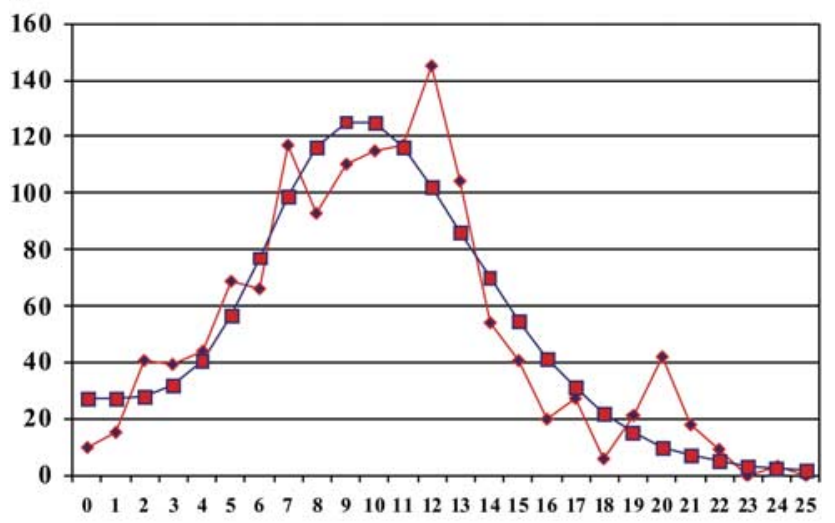

b

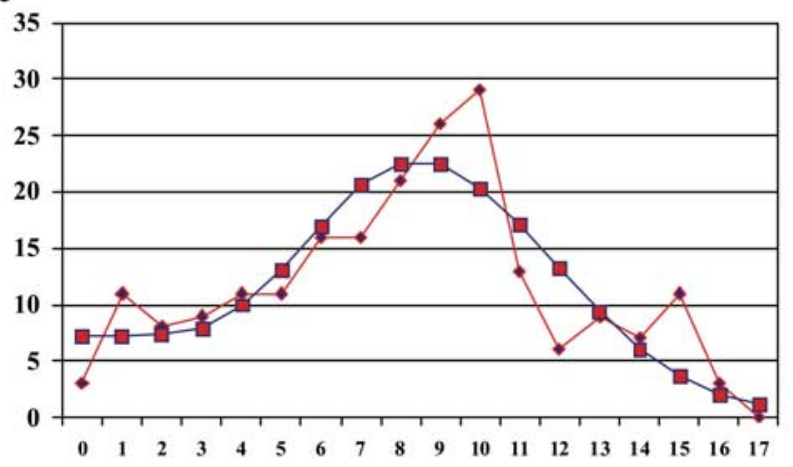

Fig. 5. Mismatch distribution for Bothrometopus huntleyi individuals from a. Marion Island (MI), and b. Prince Edward Island (PEI). Circles represent the simulated stepwise expansion model and the squares represent the observed data.

distinct clades. Clade 1 (99-100\% support) comprised three individuals from Marion Island collected from $1000 \mathrm{~m}$ a.s.1. that were basal to the second and larger clade comprising individuals from Marion Island and Prince Edward Island, suggesting that $B$. huntleyi originally colonized Marion Island at high altitude. For the remaining individuals that grouped within clade 2 , two major lineages could be discerned albeit with low levels of support. The first lineage (labelled ' $a$ ' in Fig. 3) contains individuals collected from Prince Edward Island alone, whilst lineage ' $b$ ' consists solely of individuals collected from Marion Island, the only exception being individual 317-19. Clade 2 is characterized by low bootstrap support for the internal nodes and by shallow divergences, with high support values occurring primarily at the terminal nodes. The haplotype network (Fig. 4) indicates that clade 1, the high altitude, relict population present on Marion Island, is separated from clade 2 by more than 12 steps. The two major lineages within clade 2 , namely ' $a$ ' and ' $b$ ', which correspond to Prince Edward Island and Marion Island, respectively are separated from each other by more than seven steps.

Tests for rate heterogeneity revealed that B. huntleyi lineages from the Prince Edward Islands archipelago do not

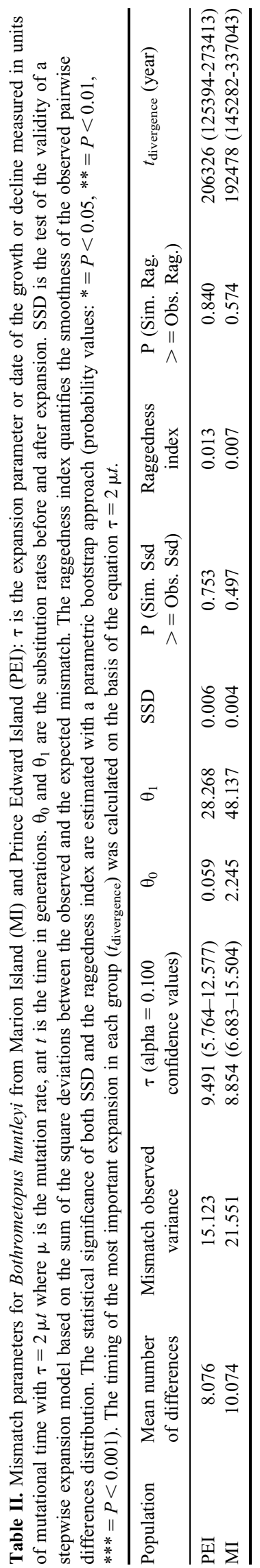


Table III. Summary statistics for Bothrometopus huntleyi from Marion Island (MI) and Prince Edward Island (PEI) showing Fu's (1997) Fs values, Tajima's (1983) D as well as estimations for $\theta$ (probability values: $*=P<0.05, * *=P<0.01, * * *=P<0.001$ ).

\begin{tabular}{|c|c|c|c|c|c|}
\hline Population & $\begin{array}{l}\text { Fu's (1997) } \\
\quad F_{s} \text { test }\end{array}$ & $\begin{array}{l}\text { Ramos-Onsins \& Rozas } \\
\text { (2002) } R_{2} \text { statistic }\end{array}$ & $\begin{array}{c}\mathrm{P}\left(\operatorname{sim}_{-} F s<=\right. \\
\text { obs_Fs })\end{array}$ & $\begin{array}{l}\text { Watterson's }(1975) \\
\text { estimate }(\theta(S))\end{array}$ & $\begin{array}{l}\text { Tajima's }(1983) \\
\text { estimate }(\theta(\pi))\end{array}$ \\
\hline PEI & $-7.686^{* *}$ & 0.081 & 0.003 & 11.952 & 8.196 \\
\hline MI & $-24.614 * * *$ & 0.053 & $<0.0001$ & 18.368 & 10.233 \\
\hline
\end{tabular}

evolve at significantly different rates. The estimated time to coalescence of $B$. huntleyi is $c$. 0.723 m.y.a., predating the oldest dated rocks, but possibly not island emergence. The first major inter-island dispersal event, is estimated to have occurred c. 0.216 million years (m.y.) later, at which time the islands were fully formed, following which $B$. huntleyi dispersed to the remainder of Marion Island during predominantly glaciations-free periods. The results indicate that subsequent to this range expansion, the populations on the two islands have remained largely isolated with the only evidence of inter-island gene flow being detected for a single haplotype (317-19). This individual, sampled from Prince Edward Island shares recent common ancestry with individual 355-1 from Long Ridge South (Fig. 3) on Marion Island, and an estimated time to coalescence of c. 0.02 m.y.a. (Fig. 3).

The mismatch distributions for individuals collected on each island are presented in Fig. 5. Neither the SSD nor the raggedness index values (Table II) showed any significant deviation from the expansion model, indicating a population expansion for both Marion Island and Prince Edward Island. The time of the main expansion events calculated using $\tau=2 \mu t$ (Table II) corresponds to $c$. 0.2 m.y. before present (BP).

Fu's $F$ s statistic (Table III) showed statistically significant and large negative values for both islands that are indicative of a population expansion ( $\mathrm{Fu}$ 1997). The $R_{2}$ statistic (Table III) of Ramos-Onsins \& Rozas (2002) also indicates population expansion. The different estimations for $\theta$ are presented in Table III.

\section{Discussion}

Time to B. huntleyi haplotype coalescence on the Prince Edward Islands archipelago is estimated to have occurred c. 0.723 m.y.a. This date is older than that of the oldest dated rocks (0.45 m.y.a.), but remains within the estimated emergence time of the islands of less than 1 m.y.a. (McDougall et al. 2001, Boelhouwers et al. 2008). It is probable that the founder population was restricted to high elevation areas of Marion Island for a period of c. 0.216 m.y. High elevation refugia in the form of nunataks have been identified for Marion Island both on geomorphological and molecular grounds (Boelhouwers et al. 2008, Mortimer et al. 2010). Moreover, recent studies from Antarctica are also providing evidence of refugia for invertebrate taxa that initially appear to be at odds with the geological evidence (Convey et al. 2008).

Bothrometopus huntleyi is estimated to have then dispersed to the remainder of Marion Island and on to
Prince Edward Island, approximately 0.507 m.y.a. This occurrence coincides with the oldest dated rocks on the island (Boelhouwers et al. 2008). Individual 317-19 from Prince Edward Island groups with individuals (92\% bootstrap support; Fig. 3) in the Marion Islandassociated lineage $b$ in clade 2 , and represents a lineage that became established on Prince Edward Island much later at c. 0.02 m.y.a. When comparing the dates estimated in Fig. 3 with the estimated times of glaciations and volcanic activity on Marion Island (Fig. 1) it can be seen that, while numerous divergence events coincide with times of volcanic activity, very few divergence events occurred during the first and third glaciations periods. Thus, it appears that genetic divergence of $B$. huntleyi is linked to volcanic activity on Marion Island, especially at those times when the island was not glaciated. Quite what mechanism of transport was involved is difficult to determine, but complex associations between volcanism and population structure are well known for animals from other island systems (e.g. Vandergast et al. 2004, Emerson et al. 2006, Moya et al. 2007).

It should be noted that for $B$. huntleyi only one instance of migration from Marion Island to Prince Edward Island occurred after Prince Edward Island was originally colonized (Fig. 1). This contrasts markedly with the multiple migration events noted for Ectemnorhinus weevils from Marion Island to Prince Edward Island (Grobler et al. 2006). The difference between $B$. huntleyi and Ectemnorhinus weevils could be explained by habitat preference. Ectemnorhinus weevils occur mainly on vegetation (Chown 1989, 1992), and are thus more likely to be transported by birds than $B$. huntleyi which mainly occurs on rock surfaces and hides in crevices in the rocks. Bothrometopus huntleyi individuals also have adhesive brushes on the tarsomeres 1-3 (Kuschel \& Chown 1995) that prevent the weevils from being easily lifted by the frequent, strong south-westerly winds.

The results of the mismatch distribution analyses are consistent with that of the phylogeny as they indicate that the major expansion event occurred on Marion Island c. 0.192 m.y.a., with lower and upper bounds of \pm 0.145 to \pm 0.337 m.y.a., respectively. Most divergence times calculated for Marion Island (Fig. 3) fall within the upper bound estimates of the mismatch analyses. Similarly, most Prince Edward Island divergence estimates (Fig. 3) also fall within the lower and upper bounds of \pm 0.125 to \pm 0.273 m.y.a., respectively as estimated by the mismatch distribution analyses which revealed that a major expansion event occurred on Prince Edward Island c. 0.206 m.y.a.. 
At present, the high elevation Marion Island founder population is intact (clade 1) and two island-discrete population complexes occur which are separated by an ocean barrier of $19 \mathrm{~km}$. Historical inter-island migration has been minimal and uni-directional (from Marion Island to Prince Edward Island only) compared to other endemic Ectemnorhinus weevils studied to date. The isolation of the population on Prince Edward Island from the population on Marion Island probably resulted from a combination of factors, including a lack of both volcanic activity and of bird and/or wind-assisted dispersal between the islands. The genetic data are thus consistent with the lack of morphological differences between the individuals found on the islands, and the assumption of a shared species. Whilst the phylogeny did not recover highly-supported island-specific clades, the haplotype network (Fig. 3) revealed that $B$. huntleyi individuals from Prince Edward Island are genetically more similar to each other than to individuals from Marion Island. It is therefore likely that these allopatric populations will continue to diverge as long as the natural inter-island isolation is maintained.

An important conservation biogeographic insight from our work is that anthropogenic gene flow between populations on Marion Island and Prince Edward Island should be prevented. Thus, the current practise of limiting visits to Prince Edward Island to a minimum, and the strict quarantine provisions for such visits (e.g. Davies et al. 2007) should be maintained. Moreover, the genetic distinctiveness of the $B$. huntleyi population on Marion Island, which is under threat via increased size-selective predation by the house mouse, Mus musculus domesticus (Chown \& Smith 1993), also underscores the need to control mice on Marion Island to ensure that both the unique genetic variation on Marion Island, and the evolutionary dynamics of the archipelago are conserved.

\section{Acknowledgements}

The authors thank I. McDougall and the Geological Magazine for the permission to use Fig. 1, taken from McDougall et al. (2001), and the referees for their helpful comments on a previous version of the ms. The Directorate Antarctica and Islands of the South African Department of Environmental Affairs and Tourism provided logistic support at Marion Island via the South African National Antarctic Programme (SANAP). This work was funded by a SANAP NRF grant (GUN2068301).

\section{References}

Alonso-Zarazaga, M.A. \& Lyal, C.H.C. 1999. A world catalogue of families and genera of Curculionoidea (Insecta: Coleoptera) excluding (Scolytidae and Platypodidae). Entomopraxis: Barcelona, 315pp.

Boelhouwers, J.C., Meiklejohn, K.I., Holness, S.D. \& Hedding, D.W. 2008. Geology, geomorphology and change. In Chown, S.L. \& Froneman, P.W., eds. The Prince Edward Islands: land-sea interactions in a changing ecosystem. Sun Press, Stellenbosch, 65-96.
BRower, A.V.Z. 1994. Rapid morphological radiation and convergence among races of the butterfly Heliconius erato inferred from patterns of mitochondrial DNA evolution. Proceedings of the National Academy of Sciences of the United States of America, 91, 6491-6495.

CHown, S.L. 1989. Habitat use and diet as biogeographic indicators for sub-Antarctic Ectemnorhinini (Coleoptera: Curculionidae). Antarctic Science, 1, 23-30.

CHOwn, S.L. 1992. A preliminary analysis of weevil assemblages in the subAntarctic: local and regional patterns. Journal of Biogeography, 19, 87-98.

Chown, S.L. \& KLок, C.L. 2003. Altitudinal body size clines: latitudinal effects associated with changing seasonality. Ecography, 26, 445-455.

Chown, S.L. \& Scholtz, C.H. 1989. Biology and ecology of the Dusmoecetes Jeannel (Col. Curculionidae) species complex on Marion Island. Oecologia, 80, 93-99.

Chown, S.L. \& Smith, V.R. 1993. Climate change and the short-term impact of feral house mice at the sub-Antarctic Prince Edward Islands. Oecologia, 96, 508-516.

Clement, M., Posada, D. \& Crandall, K. 2000. TCS: a computer program to estimate gene genealogies. Molecular Ecology, 9, 1657-1660.

Convey, P., Gibson, J.A.E., Hillenbrand, C.D., Hodgson, D.A., Pugh, P.J.A., Smellie, J.L. \& Stevens, M.I. 2008. Antarctic terrestrial life - challenging the history of the frozen continent? Biological Reviews, 83, 103-117.

Davies, S.J., Chown, S.L. \& Joubert, L.J. 2007. Renewed management systems and provisions for South Africa's sub-Antarctic islands. Papers and Proceedings of the Royal Society of Tasmania, 141, 115-120.

Dreux, P.H. \& VoIsIn, J.F. 1984. Description de Bothrometopus derelictorum, n. sp. et notes sur le genre Bothrometopus Jeannel, 1940. (Coleoptera, Curculionidae, Ectemnorrhininae). Revue Francaise d'Entomologie (N.S.), 6, 33-38.

Dreux, P.H. \& Voisin, J.F. 1986. Note sur les genres Mesembriorrhinus Jeannel et Palirhoeus Kuschel (Coleoptera, Curculionidae). Nouvelle Revue d'Entomologie (N.S.), 3, 257-261.

Drummond, A.J. \& Rambaut, A. 2007. BEAST: Bayesian evolutionary analysis by sampling trees. BMC Evolutionary Biology, 7, 214.

Emerson, B.C., Forgie, S., Goodacre, S. \& Oromi, P. 2006. Testing phylogeographic predictions on an active volcanic island: Brachyderes rugatus (Coleoptera: Curculionidae) on La Palma (Canary Islands). Molecular Ecology, 15, 449-458.

ExCOFfier, L. \& SCHNeIDER, S. 1999. Why hunter-gatherer populations do not show signs of Pleistocene demographic expansions. Proceedings of the National Academy of Sciences of the United States of America, 96, 10 597-10602.

Felsenstein, J. 1981. Evolutionary trees from DNA sequences: a maximum likelihood approach. Journal of Molecular Evolution, 17, 368-376.

Felsenstein, J. 1988. Phylogenies from molecular sequences: inference and reliability. Annual Reviews of Genetics, 22, 521-565.

Fu, Y.X. 1997. Statistical tests of neutrality of mutations against population growth, hitchhiking and background selection. Genetics, 143, 557-570.

Grobler, G.C., van Rensburg, L.J., Bastos, A.D.S., Chimimba, C.T. \& Chown, S.L. 2006. Molecular and morphometric assessment of the taxonomic status of Ectemnorhinus weevil species (Coleoptera: Curculionidae, Entiminae) from the sub-Antarctic Prince Edward Islands. Journal of Zoological Systematics and Evolutionary Research, 44, 200-211.

Grobler, G.C., Bastos, A.D.S., Treasure, A. \& Chown, S.L. 2011. Cryptic species, biogeographic complexity and the evolutionary history of the Ectemnorhinus group in the sub-Antarctic, including a description of Bothrometopus huntleyi, n. sp. Antarctic Science, 23, 10.1017/ S0954102011000101.

Guindon, S. \& GAScuEL, O. 2003. A simple, fast and accurate algorithm to estimate large phylogenies by maximum likelihood. Systematic Biology, 52, 696-704.

Hasegawa, M., Kishino, H. \& Yano, T. 1985. Dating of human-ape splitting by a molecular clock of mitochondrial DNA. Journal of Molecular Evolution, 22, 160-174. 
Huelsenbeck, J.P. \& Ronquist, F. 2001. MRBAYES: Bayesian inference of phylogeny. Bioinformatics, 17, 754-755.

Jeannel, R. 1953. Sur la faune entomologique de l'ile Marion. Revue Francaise d'Entomologie, 31, 319-417.

KuMAR, S. 1996. PHYLTEST: a program for testing phylogenetic hypothesis, version 2.0. University Park, PA: Institute of Molecular Evolutionary Genetics and Department of Biology, The Pennsylvania State University.

Kuschel, G. \& Chown, S.L. 1995. Phylogeny and systematics of the Ectemnorhinus-group of genera (Insecta: Coleoptera). Invertebrate Taxonomy, 9, 841-863.

Li, P. \& Bousquet, J. 1992. Relative-rate test for nucleotide substitutions between two lineages. Molecular Biology and Evolution, 9, 1185-1189.

Librado, P. \& Rozas, J. 2009. DnaSP v5: A software for comprehensive analysis of DNA polymorphism data. Bioinformatics, 10.1093/ bioinformatics/btp187.

McDougall, I., Verwoerd, W. \& Chevallier, L. 2001. K-Ar geochronology of Marion Island, Southern Ocean. Geological Magazine, 138, 1-17.

Mortimer, E., Jansen van Vuuren, B., Lee, J.E., Marshall, D.J., Convey, P. \& Chown, S.L. 2010. Mite dispersal among the Southern Ocean Islands and Antarctica before the last glacial maximum. Proceedings of the Royal Society of London, 10.1098/rspb.2010.1779.

Moya, O., Contreras-Diaz, H.G., Oromi, P. \& Juan, C. 2007. Phylogeography of a ground beetle species in La Gomera (Canary Islands): the effects of landscape topology and population history. Heredity, 99, 322-330.

Myburgh, M., Chown, S.L., Daniels, S.R. \& van Vuuren, B.J. 2007. Population structure, propagule pressure and conservation biogeography: lessons from indigenous and invasive springtails. Diversity and Distributions, 13, 143-154.

Papadopoulou, A., Anastasiou, I. \& Vogler, A.P. 2010. Revisiting the molecular clock: the mid-Aegean trench calibration. Molecular Biology and Evolution, 27, 1659-1672.
Posada, D. \& Crandall, K.A. 1998. MODELTEST: testing the model of DNA substitution. Bioinformatics, 14, 817-818.

Ramos-Onsins, S.E. \& Rozas, J. 2002. Statistical properties of new neutrality tests against population growth. Molecular Biology and Evolution, 19, 2092-2100.

SCHNeider, S. \& ExCOFfier, L. 1999. Estimation of past demographic parameters from the distribution of pairwise differences when the mutation rates vary among sites: application to human mitochondrial DNA. Genetics, 152, 1079-1089.

SChNeIDER, S., Roessli, D. \& Excoffier, L. 2000. Arlequin: a software for population genetics data analysis, ver. 2.000. University of Geneva, Switzerland: Genetics and Biometry Laboratory.

Stevens, M.I., Greenslade, P., Hogg, I.D. \& Sunnucks, P. 2006. Southern Hemisphere springtails: could any have survived glaciation of Antarctica? Molecular Biology and Evolution, 23, 874-882.

Swofford, D.L. 2003. PAUP*. Phylogenetic Analysis Using Parsimony ( *and other methods), version 4. Sunderland, MA: Sinauer Associates.

TалIMA, F. 1983. Evolutionary relationship of DNA sequences in finite populations. Genetics, 105, 437-460.

Tamura, K., Dudley, J., Nei, M. \& Kumar, S. 2007. MEGA4: Molecular Evolutionary Genetics Analysis (MEGA) software, version 4.0. Molecular Biology and Evolution, 24, 1596-1599.

Templeton, A.R., Crandall, K.A. \& Sing, C.F. 1992. A cladistic analysis of phenotypic associations with haplotypes inferred from restriction endonuclease mapping. III. Cladogram estimation. Genetics, 132, 619-633.

Vandergast, A.G., Gillespie, R.G. \& Roderick, G.K. 2004. Influence of volcanic activity on the population genetic structure of Hawaiian Tetragnatha spiders: fragmentation, rapid population growth and the potential for accelerated evolution. Molecular Ecology, 13, 1729-1743.

WAterhouse, C.O. 1876. Description of a new species of Ectemnorhinus from Kerguelen Island. Entomologist's Monthly Magazine, 13, 51-52.

Watterson, G.A. 1975. On the number of segregation sites. Theoretical Population Biology, 7, 256-276. 